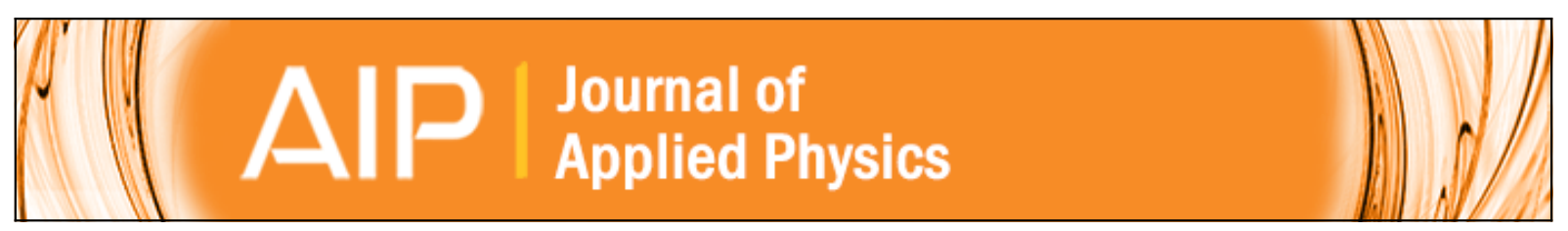

\title{
Frequency-dependence of large-signal properties in lead-free piezoceramics
}

Robert Dittmer, Wook Jo, Emil Aulbach, Torsten Granzow, and Jürgen Rödel

Citation: Journal of Applied Physics 112, 014101 (2012); doi: 10.1063/1.4730600

View online: http://dx.doi.org/10.1063/1.4730600

View Table of Contents: http://scitation.aip.org/content/aip/journal/jap/112/1?ver=pdfcov

Published by the AIP Publishing

\section{Articles you may be interested in}

Local structure change evidenced by temperature-dependent elastic measurements: Case study on

Bi1/2Na1/2TiO3-based lead-free relaxor piezoceramics

J. Appl. Phys. 115, 084108 (2014); 10.1063/1.4866092

Phase transitions, relaxor behavior, and large strain response in LiNbO3-modified Bi0.5(Na0.80K0.20)0.5TiO3 lead-free piezoceramics

J. Appl. Phys. 114, 044103 (2013); 10.1063/1.4816047

Switching of morphotropic phase boundary and large strain response in lead-free ternary

(Bi0.5Na0.5)TiO3-(K0.5Bi0.5)TiO3-(K0.5Na0.5) NbO3 system

J. Appl. Phys. 113, 114106 (2013); 10.1063/1.4795511

Piezoresponse and ferroelectric properties of lead-free [ $\mathrm{Bi} 0.5$ ( $\mathrm{Na} 0.7 \mathrm{~K} 0.2 \mathrm{Li} 0.1$ ) 0.5 ] Ti O 3 thin films by pulsed laser deposition

Appl. Phys. Lett. 92, 222909 (2008); 10.1063/1.2938364

Lead-free piezoceramics with giant strain in the system Bi 0.5 Na 0.5 Ti O $3-\mathrm{Ba} \mathrm{Ti} \mathrm{O} 3-\mathrm{K} 0.5 \mathrm{Na} 0.5 \mathrm{Nb} O 3$.

II. Temperature dependent properties

J. Appl. Phys. 103, 034108 (2008); 10.1063/1.2838476

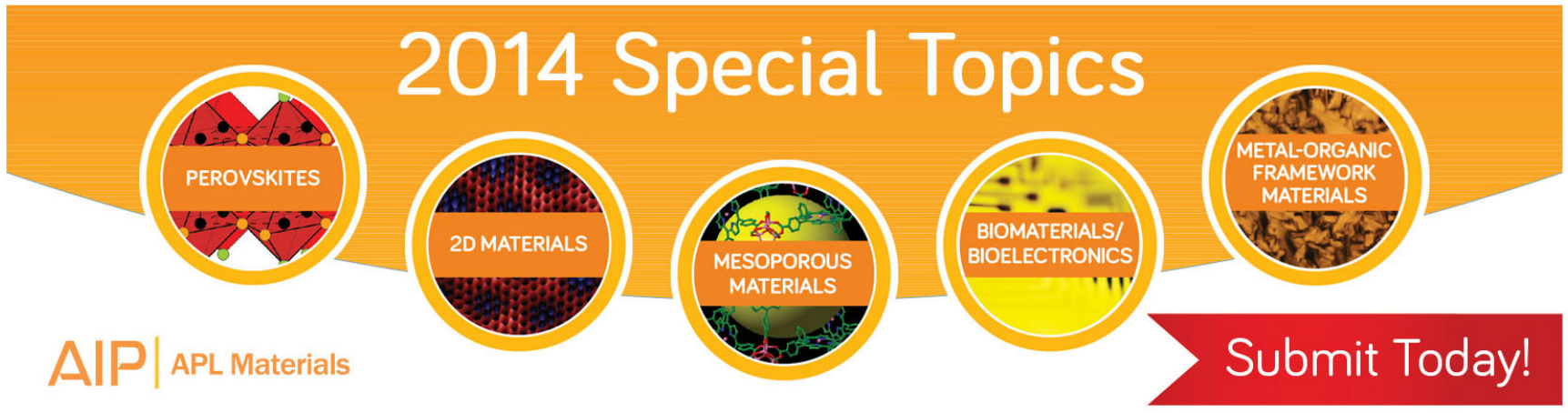




\title{
Frequency-dependence of large-signal properties in lead-free piezoceramics
}

\author{
Robert Dittmer, Wook Jo, ${ }^{\text {a) }}$ Emil Aulbach, Torsten Granzow, and Jürgen Rödel \\ Institute of Materials Science, Technische Universität Darmstadt, Petersenstr. 23, 64287 Darmstadt, Germany
}

(Received 15 December 2011; accepted 26 April 2012; published online 2 July 2012)

\begin{abstract}
The dependence of large signal properties of $(1-\mathrm{x})\left(0.81 \mathrm{Bi}_{1 / 2} \mathrm{Na}_{1 / 2} \mathrm{TiO}_{3}-0.19 \mathrm{Bi}_{1 / 2} \mathrm{~K}_{1 / 2} \mathrm{TiO}_{3}\right)$ $\mathrm{xBi}\left(\mathrm{Zn}_{1 / 2} \mathrm{Ti}_{1 / 2}\right) \mathrm{O}_{3}$ with $\mathrm{x}=0.02,0.03$, and 0.04 on the measurement frequency was investigated for a wide range of frequencies from $0.1 \mathrm{~Hz}$ to $100 \mathrm{~Hz}$. A significant frequency dispersion in the characteristic parameters representatively maximum and coercive values was denoted. On extension with the temperature dependent dielectric permittivity measurement, it was shown that the observed frequency dependence is primarily correlated with the dynamics of field-induced phase transition from a relaxor state to a long-range ferroelectric state. Increasing the substitutional disorder introduced by $\mathrm{Bi}\left(\mathrm{Zn}_{1 / 2} \mathrm{Ti}_{1 / 2}\right) \mathrm{O}_{3}$ addition was demonstrated to pronounce the frequency dependence. It was proposed that the change be due to the increase in random fields and consequent dominance of ergodicity, based on the frequency-dependent hysteresis measurements at an elevated temperature above so-called induced-ferroelectric-to-relaxor transition temperature. (C) 2012 American Institute of Physics. [http://dx.doi.org/10.1063/1.4730600]
\end{abstract}

\section{INTRODUCTION}

Piezoelectric materials have a variety of applications because of their ability in coupling electric fields and mechanical strain. ${ }^{1,2}$ Among these applications are ultrasound generation, ${ }^{3}$ energy harvesting, ${ }^{4,5}$ sensors, ${ }^{6,7}$ and actuators. ${ }^{8,9}$ However, a drawback is the incorporation of lead in most state-of-the-art materials such as $(1-\mathrm{x}) \mathrm{Pb}\left(\mathrm{Mg}_{1 / 3} \mathrm{Nb}_{2 / 3}\right) \mathrm{O}_{3}-$ $\mathrm{xPbTiO}_{3}$ (PMN-PT), $\mathrm{Pb}\left(\mathrm{Zr}_{\mathrm{x}} \mathrm{Ti}_{1-\mathrm{x}}\right) \mathrm{O}_{3}$ (PZT), or $\mathrm{Pb}_{1-\mathrm{y}} \mathrm{La}_{\mathrm{y}}$ $\left(\mathrm{Zr}_{\mathrm{x}} \mathrm{Ti}_{1-\mathrm{x}}\right) \mathrm{O}_{3}$ (PLZT), which creates an increasing conflict with the attempt to minimize the amount of lead in consumer products. Legislations like RoHS/WEEE (restriction of hazardous substances/waste electrical and electronic equipment $^{10,11}$ ) that restrict the use of lead-containing materials triggered research to find lead-free alternatives. Bismuthbased ceramics such as $\mathrm{Bi}_{1 / 2} \mathrm{Na}_{1 / 2} \mathrm{TiO}_{3}(\mathrm{BNT})$ and $\mathrm{Bi}_{1 / 2} \mathrm{~K}_{1 / 2}$ $\mathrm{TiO}_{3}$ (BKT) denote promising starting points because of the resemblance of the $\mathrm{Bi}^{3+}$ ion with the $\mathrm{Pb}^{2+}$ ion in terms of electronic configuration, i.e., a $6 \mathrm{~s}^{2}$ lone-pair configuration. ${ }^{12-15} \mathrm{As}$ $\mathrm{BNT}$ requires high switching fields and BKT is hard to fully densify by conventional sintering techniques, solid solutions of these materials were investigated. ${ }^{16,17}$ It was found that compositions at the morphotropic phase boundary (MPB) of $(1-\mathrm{x}) \mathrm{BNT}_{-\mathrm{xBaTiO}}((1-\mathrm{x}) \mathrm{BNT}-\mathrm{xBT}$, with $\mathrm{x}=0.06 \sim 0.07)$ and $(1-\mathrm{x}) \mathrm{BNT}-\mathrm{xBKT}$ (with $\mathrm{x}=0.16 \sim 0.2)$ offer enhanced electrical properties. ${ }^{18-20}$ In situ diffraction studies revealed that the morphotropic BNT-BT and BNT-BKT undergo an irreversible phase transition at a certain electric field, where the initial pseudocubic symmetry is altered towards tetragonal or tetragonal and rhombohedral mixture. ${ }^{15,21,22}$

One focal point of international research efforts is a further improvement of these materials. One way to achieve this is compositional variation by chemical modifications. Zhang et $a l .{ }^{23}$ showed that the introduction of $\left(\mathrm{K}_{0.5} \mathrm{Na}_{0.5}\right) \mathrm{NbO}_{3}$ (KNN) to $0.94 \mathrm{BNT}-0.06 \mathrm{BT}$ significantly alters the large and

\footnotetext{
a) Author to whom correspondence should be addressed. Electronic mail: jo@ceramics.tu-darmstadt.de.
}

small signal properties. They reported that the addition of KNN makes the material exhibit a notably large normalized strain $\left(S_{\max } / E_{\max }\right.$, where $S_{\max }$ and $E_{\max }$ denote the maximum strain and electric field, respectively) with the small signal piezoelectric coefficient decreasing rapidly, when $\mathrm{E}_{\max }$ exceeds $6 \mathrm{kV} / \mathrm{mm}$. Follow-up studies revealed that the large $\mathrm{S}_{\max } / \mathrm{E}_{\max }$ happens when the remanent state is absent even after electrical poling, ${ }^{24}$ and the absence of the remanent state is related to the high temperature polymorph. ${ }^{25} \mathrm{Jo} \mathrm{et} \mathrm{al}^{26}$ pro- $^{-}$ posed a reversible electric-field-induced phase transition between a "non-polar" and ferroelectric phase as the underlying mechanism.

Hinterstein et al. ${ }^{27}$ demonstrated for 0.92BNT-0.06BT$0.02 \mathrm{KNN}$ that the previously proposed reversible phase transition involves a symmetry change, i.e., from a tetragonal phase with an extremely small tetragonality of 1.0003 to a rhombohedral phase with a noticeable distortion. This phase transition was suggested as the cause for the peculiar largestrain behavior. Later on, other authors have shown that a variety of other dopants are also capable of introducing this large-strain behavior such as $\mathrm{Al}, \mathrm{Hf}$, and $\mathrm{Zr}^{28-30}$ Although specifics like the magnitude of $S_{\max } / E_{\max }$ are varying among the multitude of compositions, the basic characteristics under high fields are very similar. This can be rationalized as the base-material BNT itself is a relaxor where chemical modification with foreign elements would influence merely the relaxor features with a different degree of random fields. ${ }^{31}$

One aspect that has been overlooked is the frequencydependence of both strain and polarization hysteresis. This is, however, a crucial aspect if final applications are considered. Characterization of hystereses in academic research is often performed at around $1 \mathrm{~Hz}$ or below. In contrast, actuators as utilized, for example, in piezoelectric fuel injectors usually operate at frequencies of several tens or hundreds of hertz. ${ }^{32-35}$ This discrepancy in applied frequencies raises the question whether the above mentioned lead-free large-strain materials are subject to a significant frequency-dependence and whether they are still able to deliver high strains even at 
elevated frequencies. More importantly, the physical reason for the large strain behavior is not yet fully clarified. Therefore, a compositional study of the frequency dependence in $\mathrm{P}(\mathrm{E})$ and $\mathrm{S}(\mathrm{E})$ could deliver further insight into the underlying mechanisms in this group of materials.

Other than in lead-free materials, there are some reports on frequency-dependence of strain and polarization hysteresis for conventional piezoceramics. Chen and Viehland ${ }^{36}$ reported on $\mathrm{P}(\mathrm{E})$ and $\mathrm{S}(\mathrm{E})$ loops as a function of frequency for the soft ferroelectric 0.7PMN-0.3PT at different maximum fields. For field amplitudes below the coercive field $\left(E_{c}\right)$, they found a strong relaxation in polarization with maximum polarization $\left(\mathrm{P}_{\max }\right)$ and remanent polarization $\left(\mathrm{P}_{\mathrm{rem}}\right)$ increasing with decreasing frequencies. The field-induced strain accordingly mirrored polarization behavior. Maximum fields beyond the coercive field yielded ferroelectric hysteresis loops where $\mathrm{P}_{\text {rem }}$ and $\mathrm{P}_{\max }$ as well as $\mathrm{S}_{\text {rem }}$ and $\mathrm{S}_{\max }$ were virtually frequency-independent. However, $\mathrm{E}_{\mathrm{c}}$ and the negative strain $\left(S_{\text {neg }}\right)$ showed notable variance with both values, increasing with increasing driving frequencies, which lead to the random-field model. ${ }^{37}$ Gao et al. ${ }^{38}$ compared frequencydependent polarization loops of a soft and a hard PZT with those of $\mathrm{PZT}-\mathrm{Pb}(\mathrm{Sb}, \mathrm{Mn}) \mathrm{O}_{3}$ and also found relaxational polarization behaviors in all three materials. On the other hand, Zhang et $a l .{ }^{39}$ reported the frequency-dependent strains of a relaxor ferroelectric PLZT 9/65/35. They noted a decreasing maximum strain with increasing frequency, which was later confirmed by Shrout and Jang. ${ }^{40}$ There are more reports on the frequency dependence of the polarization loop in classical lead-containing materials for both bulk and thin film materials. ${ }^{41-45}$ For lead-free piezoelectrics, however, no systematic investigation on the effect of different driving frequencies is available in the literature yet.

In this work, we present a study of frequency-dependent high-field behavior of strain $(\mathrm{S}(\mathrm{E}))$ and polarization $(\mathrm{P}(\mathrm{E}))$ from $0.1 \mathrm{~Hz}$ to $100 \mathrm{~Hz}$ for lead-free $0.81 \mathrm{BNT}-0.19 \mathrm{BKT}$, the composition of which lies within the MPB region. ${ }^{46} \mathrm{We}$ introduced a mixed B-site occupancy of $\mathrm{Zn}^{2+}$ and $\mathrm{Ti}^{4+}$ by incorporating $\mathrm{BiZn}_{1 / 2} \mathrm{Ti}_{1 / 2} \mathrm{O}_{3}(\mathrm{BZT})$. The BZT-content in the given chemical formula, $(1-\mathrm{x})(0.81 \mathrm{BNT}-0.19 \mathrm{BKT})-\mathrm{xBZT}$, was varied from $\mathrm{x}=0.02$ to 0.04 , because they all exhibit a field-induced phase transition from a relaxor to a long-rangeordered phase but the nature of phase transition changes from an irreversible to a reversible one with increasing x. As noted, this change is featured by the appearance of a large strain with the remanent strain diminishing. We show that the large-field properties are strongly dependent on the measurement frequency and the dependence is more pronounced with increasing $\mathrm{x}$. The underlying mechanism for the frequency dependence was further enlightened by the observations compared with the frequency-dependent $\mathrm{P}(\mathrm{E})$ and $\mathrm{S}(\mathrm{E})$ of $0.98(0.81 \mathrm{BNT}-0.19 \mathrm{BKT})-0.02 \mathrm{BZT}$ at $90^{\circ} \mathrm{C}$. It is important to note that every single $\mathrm{S}(\mathrm{E})$ and $\mathrm{P}(\mathrm{E})$ measurement was performed from the virgin state. Hence, more information can be drawn from these measurements, as some important features occur exclusively in the very first half-cycle. The definition for the parameters used in the current manuscript is illustrated in Fig. 1.

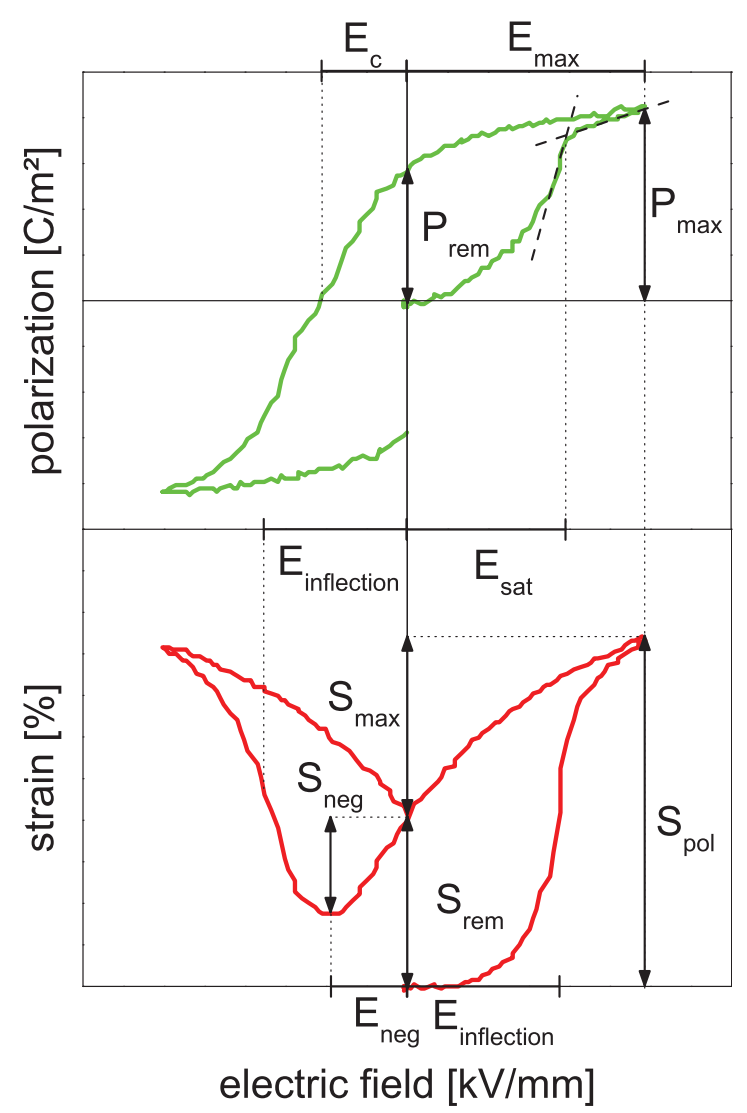

FIG. 1. Schematic illustrating characteristic parameters derived from $S(E)$ and $\mathrm{P}(\mathrm{E})$ curves.

\section{MATERIALS AND METHODS}

\section{A. Sample preparation}

The ceramic powders of the composition $(1-\mathrm{x})$ (0.81BNT-0.19BKT)-xBZT with $\mathrm{x}=0.02,0.03$, and 0.04 (in the following, termed as $2 \mathrm{BZT}, 3 \mathrm{BZT}$, and $4 \mathrm{BZT}$, respectively) were produced by the mixed oxide route from reagent grade raw powders (all Alfa Aesar GmbH \& Co. KG, Karlsruhe, Germany) $\mathrm{Bi}_{2} \mathrm{O}_{3}\left(99.975 \%\right.$ purity), $\mathrm{NaCO}_{3}(99.5 \%)$, $\mathrm{TiO}_{2}(99.9 \%), \mathrm{K}_{2} \mathrm{CO}_{3}(99.0 \%)$, and $\mathrm{ZnO}_{2}$ (99.99\%). Details of the powder processing are given elsewhere. ${ }^{47}$ The samples were shaped by uniaxial pressing using a pressing die of $10 \mathrm{~mm}$ in diameter with subsequent cold-isostatic pressing at $300 \mathrm{MPa}$. The pellets thus prepared were sintered for $3 \mathrm{~h}$ at $1100{ }^{\circ} \mathrm{C}$ in covered alumina crucibles. To minimize loss of volatile elements, the samples were covered in atmospheric powder of the respective composition. Sintered pellets were ground and polished down to $0.8 \mathrm{~mm}$ in thickness and electroded with a silver paste that was burnt in at $400^{\circ} \mathrm{C}$.

\section{B. Electrical measurements}

The polarization and strain measurements were conducted in a modified Sawyer-Tower setup with a measurement capacitance of $15 \mu \mathrm{F}$. Using an optical displacement sensor (Philtec, Inc., Annapolis, MD, USA), the accessible frequency range for $S(E)$ was greatly increased in comparison to conventional linear variable differential transformer (LVDT) sensors. Therefore, $\mathrm{P}(\mathrm{E})$ and $\mathrm{S}(\mathrm{E})$ loops could be 


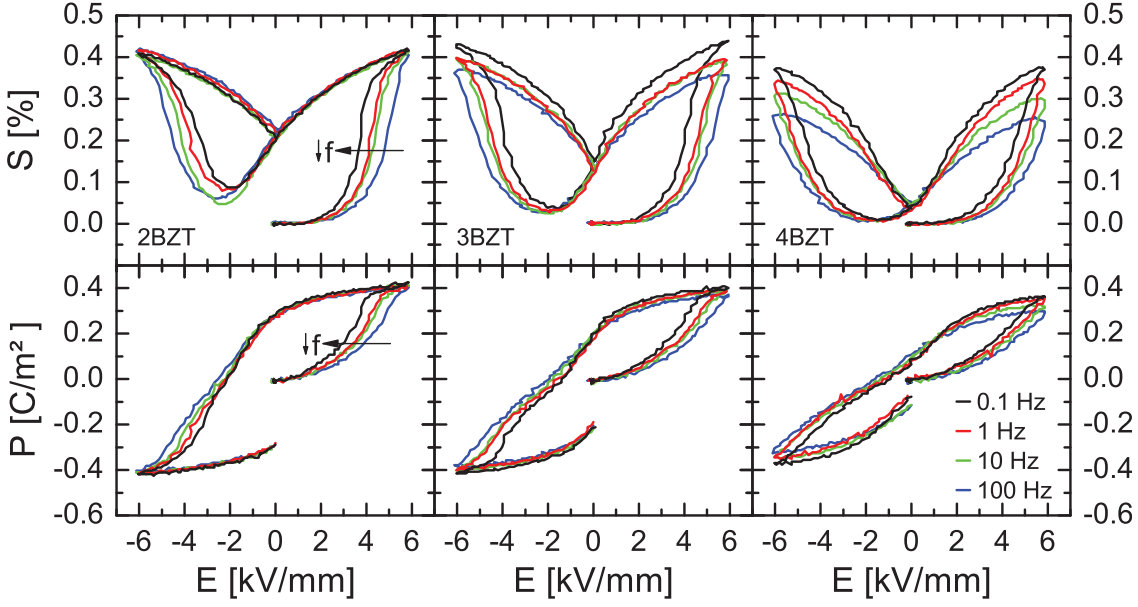

FIG. 2. Compositional evolution of frequencydependent field-induced strain $\mathrm{S}(\mathrm{E})$ and polarization $\mathrm{P}(\mathrm{E})$ with increasing $\mathrm{Zn}^{2+}$-content. recorded at $0.1 \mathrm{~Hz}, 1 \mathrm{~Hz}, 10 \mathrm{~Hz}$, and $100 \mathrm{~Hz}$, covering four orders of magnitude. To obtain virgin curves, each sample was wrapped in aluminum foil and annealed for $10 \mathrm{~min}$ at $400^{\circ} \mathrm{C}$ on a heating stage. To prevent thermal shock and cracking, the samples were cooled down to about $100^{\circ} \mathrm{C}$ before being removed from the heating stage. Temperatures were double-checked with a thermocouple, and the piezoelectric charge constant was checked with a Berlincourtmeter (Sinoceramics Inc., Shanghai, China). To obtain P(E) and $\mathrm{S}(\mathrm{E})$ loops at elevated temperatures, a temperature control was integrated into an oil bath, consisting of a resistive heating element, a temperature-controller, and a thermocouple immersed in the oil bath very close to the sample. Relative dielectric permittivity and loss factor were measured in a Nabertherm LE4/11/R6 box furnace (Nabertherm GmbH, Lilienthal, Germany) with a custom-made sample holder and an HP 4284 A impedance analyzer (Hewlett-Packard Co., Palo Alto, CA, USA) at a heating rate of $2 \mathrm{~K} / \mathrm{min}$. Prior to this measurement, the samples were poled in an oil bath at room temperature for $10 \mathrm{~min}$ under an electric field of $6 \mathrm{kV} / \mathrm{mm}$.

\section{RESULTS}

\section{A. Room temperature measurements}

Figure 2 presents the large-signal polarization and strain loops for the three compositions at $0.1 \mathrm{~Hz}, 1 \mathrm{~Hz}, 10 \mathrm{~Hz}$, and $100 \mathrm{~Hz}$. The general characteristic of $\mathrm{P}(\mathrm{E})$ and $\mathrm{S}(\mathrm{E})$ changes significantly with increasing substitution of $\mathrm{Zn}^{2+}$ for B-site. Similar to morphotropic BNT-BKT or BNT-BT, 2BZT has a high $\mathrm{P}_{\text {rem }}$ of $0.27 \mathrm{C} / \mathrm{m}^{2}$ and a high $\mathrm{S}_{\text {rem }}$ of $0.21 \%$. Both values diminish with further addition of $\mathrm{Zn}^{2+}$, eventually giving rise to the aforementioned large-strain behavior in 4BZT, which features a large strain during unipolar loading. The composition 3BZT marks an intermediate state with decreased $\mathrm{S}_{\text {rem }}$ of $0.13 \%$ and $\mathrm{P}_{\text {rem }}$ of $0.17 \mathrm{C} / \mathrm{m}^{2}$.

A salient feature is the distinct frequency-dependence that is found for all three compositions, albeit with significantly different aspects. In all compositions, the relevant field parameters, i.e., the coercive field $\left(\mathrm{E}_{\mathrm{c}}\right)$, the field defined by the maximum slope in the $\mathrm{S}(\mathrm{E})$ curve $\left(\mathrm{E}_{\text {inflection }}\right)$, as well as the field for maximum negative strain $\left(E_{n e g}\right)$, increase with increasing frequency as illustrated in Fig. 3. Moreover, $S_{\text {rem }}$ and $\mathrm{P}_{\mathrm{rem}}$ remain unchanged in all samples, but in $3 \mathrm{BZT}$ and
4BZT, the poling strain $\left(\mathrm{S}_{\mathrm{pol}}\right)$ is very sensitive to frequency changes as depicted in Fig. 4. Consequently, the normalized strain $S_{\max } / E_{\max }$ drops notably when the frequency is increased. In the case of $4 \mathrm{BZT}, \mathrm{S}_{\max } / \mathrm{E}_{\max }$ decreases from $580 \mathrm{pm} / \mathrm{V}$ for $0.1 \mathrm{~Hz}$ down to $340 \mathrm{pm} / \mathrm{V}$ for $100 \mathrm{~Hz}$, which denotes a drop by as large as $\sim 41 \%$.

\section{B. Measurements at elevated temperatures}

Measurements of dielectric properties from room temperature up to $400{ }^{\circ} \mathrm{C}$ for frequencies from $1 \mathrm{kHz}$ up to $1 \mathrm{MHz}$ are presented in Fig. 5. All three compositions exhibit very similar behavior in $\varepsilon_{\mathrm{r}, 33}(\mathrm{~T})$ and $\tan \delta(\mathrm{T})$. The dielectric permittivity features a broad maximum at around $300{ }^{\circ} \mathrm{C}$ with a low-temperature shoulder. The frequency dispersion

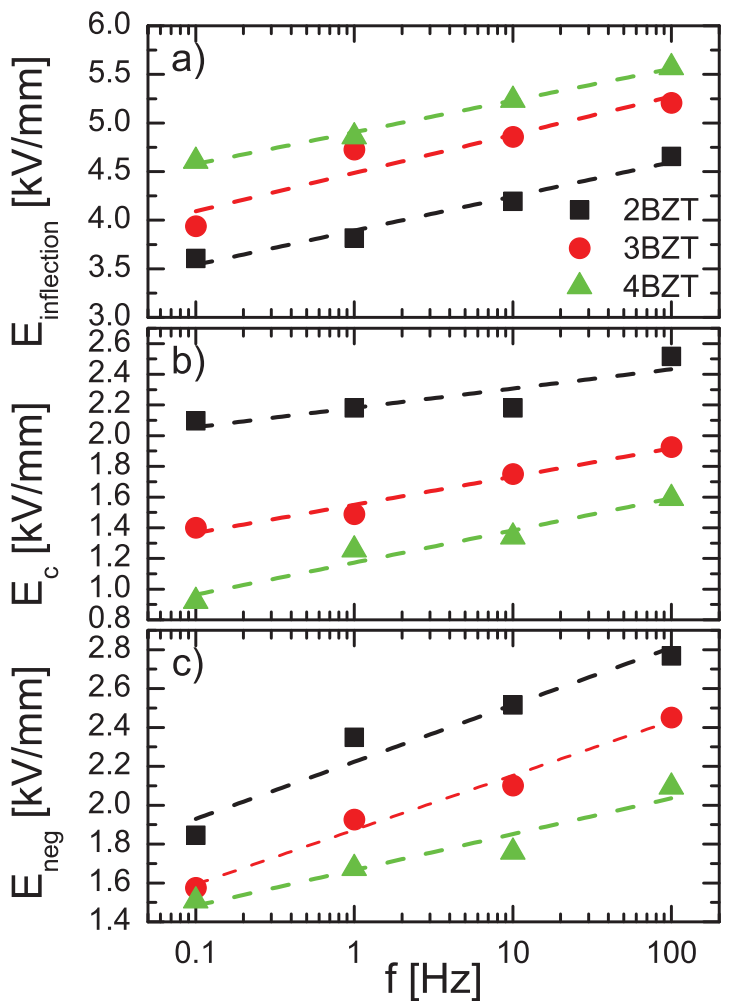

FIG. 3. Characteristic fields determined from frequency dependent measurements for 2BZT, 3BZT, and 4BZT: (a) field of maximum slope in $\mathrm{S}(\mathrm{E})$ curve $\mathrm{E}_{\text {inflection, }}(\mathrm{b})$ coercive field $\mathrm{E}_{\mathrm{c}}$, and (c) field of negative strain $\mathrm{E}_{\text {neg. }}$. 


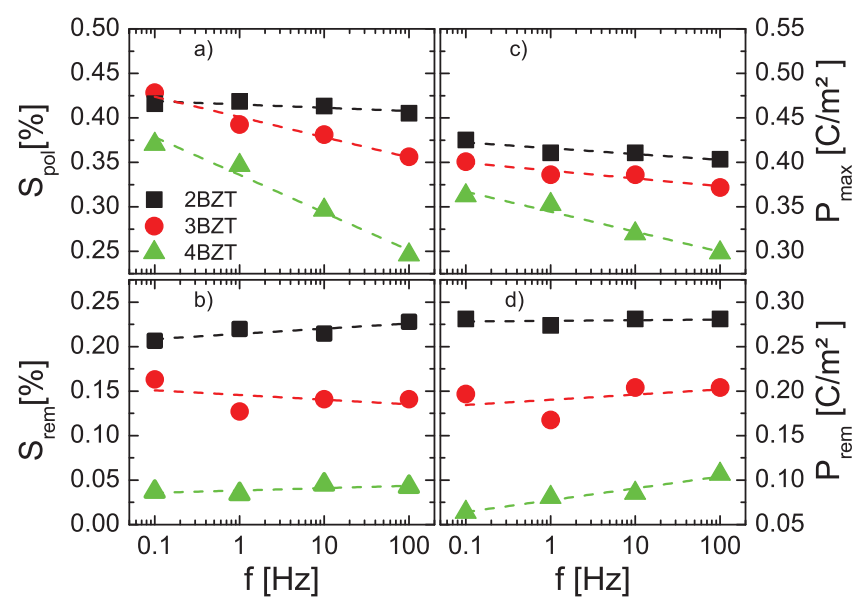

FIG. 4. Strain and polarization parameters derived from the frequency dependent measurements for 2BZT, 3BZT, and 4BZT: (a) poling strain, $\mathrm{S}_{\mathrm{pol}}$, (b) remanent strain, $\mathrm{S}_{\mathrm{rem}}$, and (c) maximum polarization, $\mathrm{P}_{\max }$, remanent polarization, $\mathrm{P}_{\text {rem }}$.

in the low-temperature region of $\varepsilon_{\mathrm{r}, 33}$ is also reflected in $\tan \delta$, which is an indication for relaxor behavior. ${ }^{31}$ The nearly frequency-independent first peak in $\tan \delta$ has been taken in the literature to characterize the depolarization temperature. ${ }^{18}$ Recent work contrasting temperature dependence of dielectric permittivity, depolarization current, and piezoelectric coefficient demonstrated that the temperature found using $\tan \delta$ is above the true depolarization temperature. ${ }^{47}$ This was ascertained using further field dependence together with temperature dependence of permittivity and depolarization current. ${ }^{48}$ Here, we are fundamentally interested in ferroelectric-relaxor transitions and determine the peak in $\tan \delta$ in order to quantify the ferroelectric-relaxor transition $\left.\left(\mathrm{T}_{\mathrm{F}-\mathrm{R}}\right)\right)^{31,48}$ This temperature decreases with increasing $\mathrm{Zn}^{2+}$-content from $55^{\circ} \mathrm{C}$ in $2 \mathrm{BZT}$ to $45^{\circ} \mathrm{C}$ in $3 \mathrm{BZT}$. Eventually, no transition is observed for $4 \mathrm{BZT}$ above $25^{\circ} \mathrm{C}$. The general trend suggests that the ferroelectric-relaxor transition lies below room temperature.
Figure 6 presents the field-induced strain and polarization of $2 \mathrm{BZT}$ at $90^{\circ} \mathrm{C}$. This temperature was chosen because it lies well above $\mathrm{T}_{\mathrm{F}-\mathrm{R}}$. It is obvious that the increase in temperature has a dramatic effect on the strain response. First, the remanent strain, $S_{\text {rem }}$ drops from about $0.2 \%$ down to about $0.1 \%$. Moreover $S_{\text {rem }}$ appears to vary with frequency, whereas it is invariant at room temperature. The difference in $S_{\text {rem }}$ with frequency, however, is only pronounced between $0.1 \mathrm{~Hz}$ and $1 \mathrm{~Hz}$. The change in $S_{\text {rem }}$ above $1 \mathrm{~Hz}$ is so small and non-systematic that it may be induced by temperature fluctuation and consequent thermal drifting effects. In contrast to $S_{\text {rem }}$ and unlike the room-temperature behavior of $2 \mathrm{BZT}$, the maximum strain during poling $\left(\mathrm{S}_{\mathrm{pol}}\right)$ strongly depends on frequency: the sample delivers almost $0.2 \%$ less strain at the frequency of $100 \mathrm{~Hz}$ in comparison to $100 \mathrm{mHz}$. Nonetheless, the maximum strain at $90{ }^{\circ} \mathrm{C}$ is significantly larger than that at room temperature for all frequencies due to the drop in the remanent strain. Consequently, $\mathrm{S}_{\max } / \mathrm{E}_{\max }$ is increased from virtually frequency-independent $350 \mathrm{pm} / \mathrm{V}$ at room temperature to $445 \mathrm{pm} / \mathrm{V}$ at $100 \mathrm{~Hz}$ and $606 \mathrm{pm} / \mathrm{V}$ at $100 \mathrm{mHz}$. Therefore, $2 \mathrm{BZT}$ provides a strain response at $90{ }^{\circ} \mathrm{C}$ that is to some extent comparable to the room-temperature response of $4 \mathrm{BZT}$, which was also shown to exhibit frequency-dependent large-strain behavior. Compared to room temperature, the $\mathrm{P}(\mathrm{E})$ loop at $90{ }^{\circ} \mathrm{C}$ is notably slimmer and slightly pinched, which again resembles the compositional evolution illustrated in Fig. 2. The remanent polarization decreased from about $0.27 \mathrm{C} / \mathrm{m}^{2}$ down to $0.12 \mathrm{C} / \mathrm{m}^{2}$ with the maximum polarization virtually unchanged at about $0.42 \mathrm{C} / \mathrm{m}^{2}$. For the $1 \mathrm{~Hz}$ measurement, this corresponds to a back-switching $\left(\mathrm{P}_{\max }-\mathrm{P}_{\text {rem }}\right) / \mathrm{P}_{\max }$ of $33 \%$ at room temperature and $73 \%$ at $90{ }^{\circ} \mathrm{C}$. That value is higher than the $57 \%$ back-switching observed in $3 \mathrm{BZT}$ at $1 \mathrm{~Hz}$ and close to the $78 \%$ found for the same frequency in $4 \mathrm{BZT}$. Despite the similarities between $2 \mathrm{BZT}$ at $90^{\circ} \mathrm{C}$ and $4 \mathrm{BZT}$ at room temperature, there are some noticeable differences. The maximum polarization in 2BZT is frequency-independent whereas it

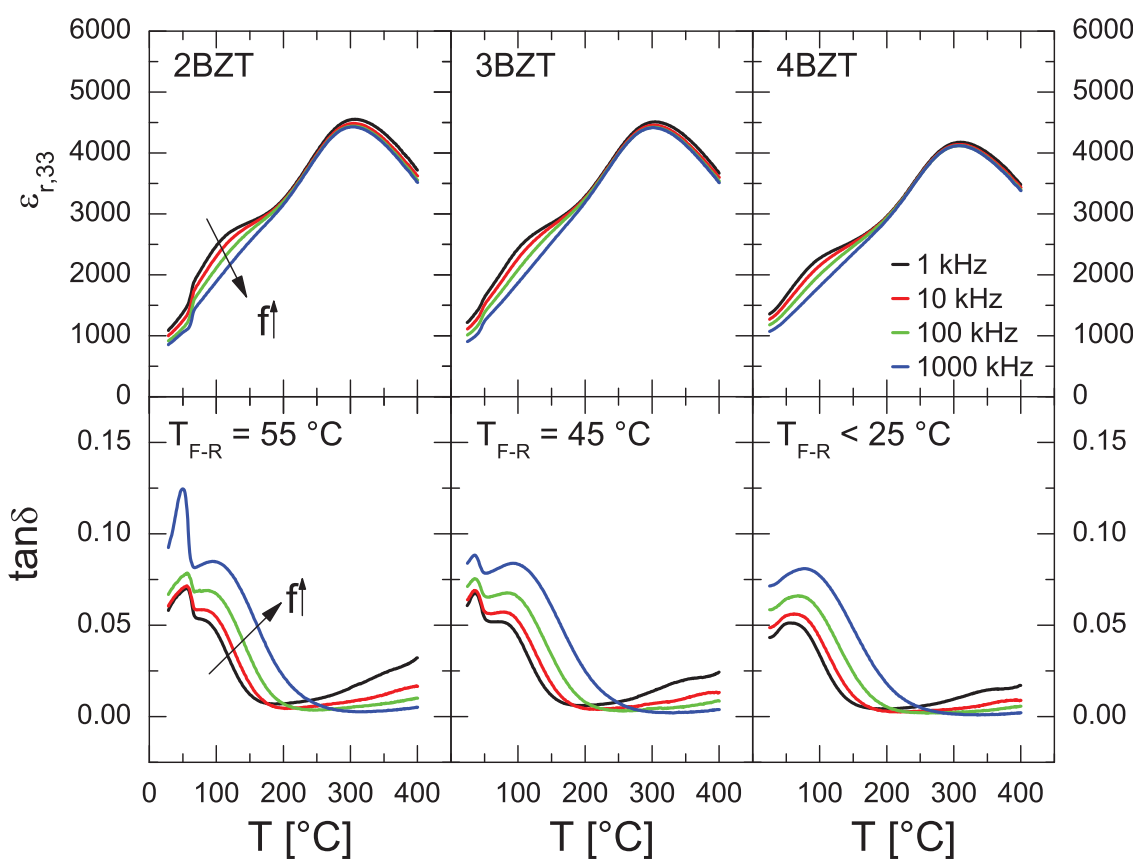

FIG. 5. Relative dielectric permittivity $\varepsilon_{\mathrm{r}, 33}$ and loss factor $\tan \delta$ of poled samples at various frequencies. 


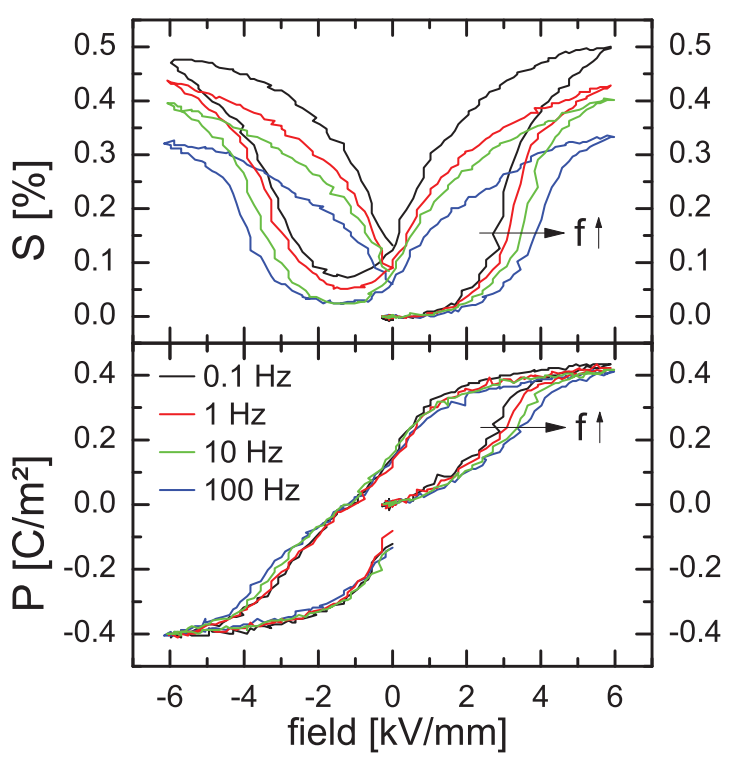

FIG. 6. Frequency-dependent strain $\mathrm{S}(\mathrm{E})$ and polarization $\mathrm{P}(\mathrm{E})$ of $2 \mathrm{BZT}$ at $90{ }^{\circ} \mathrm{C}$.

varies in $4 \mathrm{BZT}$, if only to a small extent. Moreover, a distinguishable field, $\mathrm{E}_{\mathrm{sat}}$ can be determined in 2BZT where the polarization saturates during the first half-cycle at room temperature and $90^{\circ} \mathrm{C}$. At both temperatures, $\mathrm{E}_{\mathrm{sat}}$ is frequencydependent, shifting to higher electric fields with increasing frequency. This saturation field in $\mathrm{P}(\mathrm{E})$ correlates with the $E_{\text {inflection }}$ in the $S(E)$ curve, i.e., a sharp increase in strain is observed just below $\mathrm{E}_{\mathrm{sat}}$. Figure 7 illustrates this correlation. It is obvious that both $\mathrm{E}_{\mathrm{sat}}$ and $\mathrm{E}_{\text {inflection }}$ decrease for all frequencies at the elevated temperature. For example, $\mathrm{E}_{\mathrm{sat}}$ at $1 \mathrm{~Hz}$ is reduced from $4.6 \mathrm{kV} / \mathrm{mm}$ at room temperature down to $3.6 \mathrm{kV} / \mathrm{mm}$ at $90^{\circ} \mathrm{C}$. In $4 \mathrm{BZT}, \mathrm{P}(\mathrm{E})$ does not saturate and, therefore, no $\mathrm{E}_{\mathrm{sat}}$ can be defined.

\section{DISCUSSION}

We have found significant influences of measurement frequency on large-signal behaviors, ranging from $0 \%$ to $41 \%$ in $S_{\max } / E_{\max }$ depending on extension of ferroelectric order. In contrast, lead-containing materials often show no

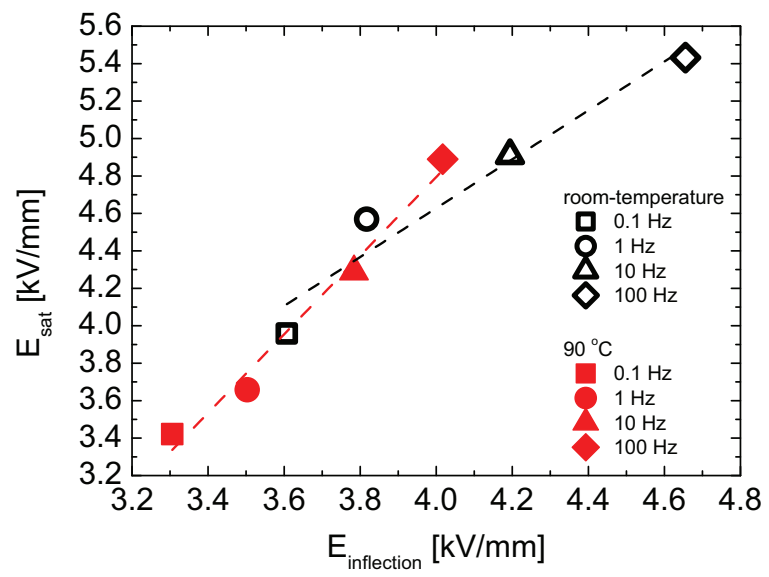

FIG. 7. Correlation of $\mathrm{E}_{\text {sat }}$ determined from $\mathrm{P}(\mathrm{E})$ and $\mathrm{E}_{\text {inflection determined }}$ from $\mathrm{S}(\mathrm{E})$ for $2 \mathrm{BZT}$ at room-temperature and $90^{\circ} \mathrm{C}$. such pronounced frequency dependence of strain as demonstrated for soft PZT or 70-PMN-30PT. ${ }^{36-38}$ On the other hand, the relaxor material PLZT 9/65/35 features a strain response that is likewise dependent on frequency where $S_{\max }$ decreases by about $20 \%$ when the driving frequency is increased from $1 \mathrm{~Hz}$ to $100 \mathrm{~Hz}$. ${ }^{39}$

To explain the evolution of $\mathrm{S}(\mathrm{E})$ and $\mathrm{P}(\mathrm{E})$ illustrated in Fig. 2, we therefore suggest that BNT-BKT-BZT is a relaxor ferroelectric that undergoes a field-induced transition from a relaxor to a state with a ferroelectric long-range order. ${ }^{46}$ This transition is highly dependent on the applied field, but also on composition, frequency, and temperature. We assume that below a field limit, polar nanoregions (PNRs) exist, but ferroelectric macrodomains do not. Upon passing a critical field, a transition with the development of ferroelectric longrange order occurs. With a little mixed B-site occupation, as in $2 \mathrm{BZT}$, the field required to induce the phase transition is comparably low. Therefore, 2BZT can be poled at moderate electric fields; hence, appears ferroelectric under high fields and possesses a sizable small signal $d_{33}$ of $139 \mathrm{pC} / \mathrm{N}$. In an earlier report, we found via high-energy in situ XRD under electric field that $\mathrm{E}_{\mathrm{sat}}$ is correlated with the critical field, where a long-range order is established and non-cubic distortion is detected. ${ }^{46}$ For $2 \mathrm{BZT}$, this means that the transition takes place in the range of $\mathrm{E}_{\mathrm{sat}}$ around $4 \mathrm{kV} / \mathrm{mm}$ at $100 \mathrm{mHz}$. The $\mathrm{P}(\mathrm{E})$ loop of $2 \mathrm{BZT}$ shows practically no constriction, which implies that the induced ferroelectric order is comparably stable on the removal of electric field. This observation suggests that the transition is from a non-ergodic relaxor state to a ferroelectric.

Increasing the dopant content progressively impedes the creation of ferroelectric long-range order as indicated by $\mathrm{E}_{\mathrm{sat}}$ which increased from $4 \mathrm{kV} / \mathrm{mm}$ in $2 \mathrm{BZT}$ to $4.6 \mathrm{kV} / \mathrm{mm}$ in $3 \mathrm{BZT}$ at $100 \mathrm{mHz}$. This result can be rationalized by the higher fraction of $\mathrm{Zn}^{2+}$ ions that occupy the B-site of perovskite lattice in 3BZT and cause a higher degree of disorder. This increased substitutional charge disorder implicates an augmentation of random fields. Consequently, the establishment of a long-range order is restrained. In 4BZT, no saturation polarization is reached with fields up to $6 \mathrm{kV} / \mathrm{mm}$, i.e., the transition is even more impeded by the increased $\mathrm{Zn}^{2+}$ content. During the reduction of electric field, the induced long-range order collapses and consequently $\mathrm{P}_{\text {rem }}$ and $\mathrm{S}_{\mathrm{rem}}$ are diminished, meaning that the relaxational behavior is due to a series of transitions from an ergodic relaxor to an induced ferroelectric and back to the ergodic relaxor. However, the non-zero remanence suggests that the long-range order still persists in some volume fraction of the samples. This can also be grasped by the pinched polarization loop in $3 \mathrm{BZT}$ and $4 \mathrm{BZT}$, which indicates that at least a part of the induced long-range order is not stable in the absence of external field.

A similar behavior has been ascertained in fielddependent transmission electron microscopy on the ergodic relaxor $0.91 \mathrm{BNT}-0.06 \mathrm{BT}-0.03 \mathrm{KNN}$, where ferroelectric domains appeared and disappeared with increasing and decreasing electric field, respectively. ${ }^{49}$ Similarly, the reversible phase transition has been demonstrated both with synchrotron as well as with neutron diffraction on 0.92BNT-0.06BT- 
$0.02 \mathrm{KNN}^{27}$ In the case of $0.92 \mathrm{BNT}-0.06 \mathrm{BT}-0.02 \mathrm{KNN}$ and 0.91BNT-0.06BT-0.03KNN, ferroelectric domains appear with crystallographic symmetry changing, which could be interrogated with diffraction techniques applied.

The same argument applies to the high-temperature measurement presented in Fig. 6, where it is not the substitutional charge disorder but the thermal excitation that causes the instability of the ferroelectric long-range order. Ultimately, the large signal behavior of $2 \mathrm{BZT}$ at $90^{\circ} \mathrm{C}$ mimics that of $4 \mathrm{BZT}$ at room temperature, i.e., a transition takes place from ergodic relaxor to a ferroelectric. Upon removal of the electric field, the majority of the long-range order collapses, and the ergodic relaxor state is recovered with only a minute remanence. The frequency dependence of strain and polarization in 2BZT underpins the assumption of a transition from non-ergodic to a long-range ferroelectric state. Since $\mathrm{E}_{\mathrm{sat}}$ depends on frequency, it is concluded that the field-induced phase transition is also frequency-dependent in a sense that the transition is triggered at lower fields for lower frequencies. The observed time dependence suggests that the mechanism of the transition be associated with coalescence of PNRs. Under the electric field, the PNRs start to grow in size until they eventually overcome the existing random field to form ferroelectric domains. In the case of 2BZT, the maximum field of $6 \mathrm{kV} / \mathrm{mm}$ is sufficient for the material to be fully converted into the ferroelectric state. Therefore, $S_{\max }$ and $\mathrm{P}_{\max }$ are virtually frequencyindependent. This is, however, not true at lower fields as evidenced by a significant frequency dispersion of $S(E)$, e.g., at $4 \mathrm{kV} / \mathrm{mm}$, where strain during the first half-cycle is $0.3 \%$ at $100 \mathrm{mHz}$ and only $0.07 \%$ at $100 \mathrm{~Hz}$. The physical reason is the incomplete transition into a long-range-ordered state.

Other than in $2 \mathrm{BZT}$, the frequency dispersion persists in $3 \mathrm{BZT}$ and $4 \mathrm{BZT}$ up to the maximum field of $6 \mathrm{kV} / \mathrm{mm}$. As presented in Fig. 4, the frequency dispersion increases with increasing $\mathrm{Zn}^{2+}$-content. This observation is in agreement with the assumption of a material that exhibits ergodicity to some extent. Because of the weakly correlated PNRs, there is a distribution of relaxation times. Consequently, the properties under field are highly frequencydependent. The same frequency dependence is introduced in 2BZT when the sample is heated beyond $T_{F-R}$, which is associated with a transition from the nonergodic to the ergodic relaxor state.

\section{SUMMARY AND CONCLUSION}

We presented a compositional study of frequencydependent field-induced strain and polarization in lead-free morphotropic BNT-BKT doped with $\mathrm{Zn}^{2+}$ on the B-site of the perovskite lattice. It was found that the field-induced phase transition does not only depend on field and composition but also frequency and temperature. It was shown that the higher the frequencies are, the higher the field for the phase transition to take place, which is a clear evidence that the transition is time-dependent. For a low content of B-site dopants (as in 2BZT), the coercive field in the $\mathrm{P}(\mathrm{E})$ loop demonstrates very little frequency-dependence, which is in contrast to lead-containing soft ferroelectrics. At room temperature, both maximum strain and polarization are likewise frequency-independent within the considered frequency range from $100 \mathrm{mHz}$ to $100 \mathrm{~Hz}$. For temperatures beyond $\mathrm{T}_{\mathrm{F}-\mathrm{R}}$, however, it was shown that frequency dispersion emerges, most likely due to the appearance of ergodicity.

For a higher degree of mixed B-site occupation, the maximum strain is strongly frequency-dependent even at room temperature, where the formation of ferroelectric longrange order is suggested being impeded by the increased $\mathrm{Zn}^{2+}$ content. The normalized strain $\mathrm{S}_{\max } / \mathrm{E}_{\max }$ was shown to decrease by about $40 \%$ when the frequency is increased from $100 \mathrm{mHz}$ to $100 \mathrm{~Hz}$. These high frequencies, however, are often required for actuator applications. Consequently, a clear understanding of the described frequency dependence is crucial for the potential utilization of lead-free materials.

\section{ACKNOWLEDGMENTS}

This work was financially supported by the Deutsche Forschungsgemeinschaft (DFG) under SFB 595.

${ }^{1}$ D. Damjanovic, Rep. Prog. Phys. 61, 1267 (1998).

${ }^{2}$ B. Jaffe, W. R. Cook, and H. Jaffe, Piezoelectric Ceramics (Academic, London, 1971), Vol. 115.

${ }^{3}$ B. W. Drinkwater and P. D. Wilcox, NDT \& E Int. 39, 525 (2006).

${ }^{4}$ S. R. Anton and H. A. Sodano, Smart Mater. Struct. 16, R1 (2007).

${ }^{5}$ S. P. Beeby, M. J. Tudor, and N. M. White, Meas. Sci. Technol. 17, R175 (2006).

${ }^{6}$ P. B. Luppa, L. J. Sokoll, and D. W. Chan, Clin. Chim. Acta 314, 1 (2001).

${ }^{7}$ P. Leonard, S. Hearty, J. Brennan, L. Dunne, J. Quinn, T. Chakraborty, and R. O'Kennedy, Enzyme Microb. Technol. 32, 3 (2003).

${ }^{8}$ H. S. Tzou, H. J. Lee, and S. M. Arnold, Mech. Adv. Mater. Struct. 11, 367 (2004).

${ }^{9}$ E. K. Akdogan, M. Allahverdi, and A. Safari, IEEE Trans. Ultrason. Ferroelectr. Freq. Control 52, 746 (2005).

${ }^{10}$ The European Parliament and the Council of the European Union, Off J. Eur. Union 46, 19 (2003).

${ }^{11}$ The European Parliament and the Council of the European Union, Off. J. Eur. Union 46, 24 (2003).

${ }^{12}$ M. R. Suchomel, A. M. Fogg, M. Allix, H. J. Niu, J. B. Claridge, and M. J. Rosseinsky, Chem. Mater. 18, 4987 (2006).

${ }^{13}$ G. A. Smolenskii and A. I. Agranovskaya, Sov. Phys. Solid State 1, 1429 (1960).

${ }^{14}$ G. A. Smolenskii, V. A. Isupov, A. I. Agranovskaya, and N. N. Krainik, Sov. Phys. Solid State 2, 2651 (1961).

${ }^{15}$ A. J. Royles, A. J. Bell, A. P. Jephcoat, A. K. Kleppe, S. J. Milne, and T. P. Comyn, Appl. Phys. Lett. 97, 132909 (2010).

${ }^{16}$ J. Rödel, W. Jo, K. T. P. Seifert, E. M. Anton, T. Granzow, and D. Damjanovic, J. Am. Ceram. Soc. 92, 1153 (2009).

${ }^{17}$ T. Takenaka and H. Nagata, J. Eur. Ceram. Soc. 25, 2693 (2005).

${ }^{18}$ T. Takenaka, K. Maruyama, and K. Sakata, Jpn. J. Appl. Phys., Part 130 , 2236 (1991).

${ }^{19}$ Y. Hiruma, H. Nagata, and T. Takenaka, J. Appl. Phys. 104, 124106 (2008).

${ }^{20}$ A. Sasaki, T. Chiba, Y. Mamiya, and E. Otsuki, "Dielectric and piezoelectric properties of $\left(\mathrm{Bi}_{0.5} \mathrm{Na}_{0.5}\right) \mathrm{TiO}_{3}-\left(\mathrm{Bi}_{0.5} \mathrm{~K}_{0.5}\right) \mathrm{TiO}_{3}$ systems," Jpn. J. Appl. Phys., Part 1 38, p. 5564 (1999).

${ }^{21}$ J. E. Daniels, W. Jo, J. Rodel, and J. L. Jones, Appl. Phys. Lett. 95, 032904 (2009).

${ }^{22}$ H. Simons, J. Daniels, W. Jo, R. Dittmer, A. Studer, M. Avdeev, J. Rödel, and M. Hoffman, Appl. Phys. Lett. 98, 082901 (2011).

${ }^{23}$ S. T. Zhang, A. B. Kounga, E. Aulbach, H. Ehrenberg, and J. Rödel, Appl. Phys. Lett. 91, 112906 (2007).

${ }^{24}$ S. T. Zhang, A. B. Kounga, E. Aulbach, T. Granzow, W. Jo, H. J. Kleebe, and J. Rödel, J. Appl. Phys. 103, 034107 (2008).

${ }^{25}$ S. T. Zhang, A. B. Kounga, E. Aulbach, W. Jo, T. Granzow, H. Ehrenberg, and J. Rödel, J. Appl. Phys. 103, 034108 (2008). 
${ }^{26}$ W. Jo, T. Granzow, E. Aulbach, J. Rodel, and D. Damjanovic, J. Appl. Phys. 105, 094102 (2009).

${ }^{27}$ M. Hinterstein, M. Knapp, M. Hölzel, W. Jo, A. Cervellino, and H. Ehrenberg, J. Appl. Crystallogr. 43, 1314 (2010).

${ }^{28}$ A. Ullah, C. W. Ahn, A. Hussain, S. Y. Lee, H. J. Lee, and I. W. Kim, Curr. Appl. Phys. 10, 1174 (2010).

${ }^{29}$ A. Hussain, C. W. Ahn, A. Ullah, J. S. Lee, and I. W. Kim, Jpn. J. Appl. Phys., Part 1 49, 041504 (2010).

${ }^{30}$ A. Hussain, C. W. Ahn, J. S. Lee, A. Ullah, and I. W. Kim, Sens. Actuators, A 158, 84 (2010).

${ }^{31}$ W. Jo, S. Schaab, E. Sapper, L. A. Schmitt, H.-J. Kleebe, A. J. Bell, and J. Rödel, J. Appl. Phys. 110, 074106 (2011).

${ }^{32}$ M. S. Senousy, F. X. Li, D. Mumford, M. Gadala, and R. K. N. D. Rajapakse, J. Intell. Mater. Syst. Struct. 20, 387 (2009).

${ }^{33}$ M. S. Senousy, R. K. N. D. Rajapakse, D. Mumford, and M. S. Gadala, Smart Mater. Struct. 18, 045008 (2009).

${ }^{34} \mathrm{~F}$. Zunqiang, L. Jianfang, Y. Zhigang, and L. Jianqiao, in Study on the Control of Precise Actuator with Piezoelectric Stack Pump (2010), p. 738.

${ }^{35}$ S. Sherrit, B. Xiaoqi, C. M. Jones, J. B. Aldrich, C. J. Blodget, J. D. Moore, J. W. Carson, R. Goullioud, and B. Jau, in Piezoelectric Stack Actuator Life Test (2011), p. 1.

${ }^{36}$ Y. H. Chen and D. Viehland, Appl. Phys. Lett. 77, 133 (2000).
${ }^{37}$ D. Viehland and Y. H. Chen, J. Appl. Phys. 88, 6696 (2000).

${ }^{38}$ Y. Gao, K. Uchino, and D. Viehland, J. Appl. Phys. 92, 2094 (2002).

${ }^{39}$ Q. M. Zhang, S. J. Jang, and L. E. Cross, J. Appl. Phys. 65, 2807 (1989).

${ }^{40}$ T. R. Shrout and S.-J. Jang, Relaxor Ferroelectrics for Electrostrictive Transducer, in Quarterly Report Sep. 1991 - 31 Jan. 1992 Pennsylvania State Univ., University Park Materials Research Lab (1992).

${ }^{41}$ M. H. Lente, A. Picinin, J. P. Rino, and J. A. Eiras, J. Appl. Phys. 95, 2646 (2004).

${ }^{42}$ Y. H. Chen, K. Uchino, and D. Viehland, J. Appl. Phys. 89, 3928 (2001).

${ }^{43}$ R. Yimnirun, S. Wongsaenmai, S. Ananta, and Y. Laosiritaworn, Appl. Phys. Lett. 89, 242901 (2006).

${ }^{44}$ X. F. Chen, X. L. Dong, N. B. Feng, H. C. Nie, F. Cao, G. S. Wang, Y. $\mathrm{Gu}$, and H. L. He, Solid State Commun. 149, 663 (2009).

${ }^{45}$ J. F. Scott, Integr. Ferroelectr. 12, 71 (1996).

${ }^{46}$ R. Dittmer, W. Jo, J. Daniels, S. Schaab, and J. Rödel, J. Am. Ceram. Soc. 94, 4283 (2011).

${ }^{47}$ E. M. Anton, W. Jo, J. Trodahl, D. Damjanovic, and J. Rödel, Jpn. J. Appl. Phys., Part 1 50, 055802 (2011).

${ }^{48}$ E. Sapper, S. Schaab, W. Jo, T. Granzow, and J. Rödel, J. Appl. Phys. 111, 014105 (2012).

${ }^{49}$ J. Kling, X. Tan, W. Jo, H.-J. Kleebe, H. Fuess, and J. Rödel, J. Am. Ceram. Soc. 93, 2452 (2010). 